\title{
Indocyanine Green Videoangiography in Clipping of Paraclinoid Aneurysms
}

\author{
Paraklinoid Anevrizmalarn Kliplenmesinde Indosiyanin Yeşil \\ Videoanjiyografi
}

\author{
Jihui LIU, Xinguo LI, Shengxue SUN, Yunjie WANG, Peizhuo ZANG \\ First Affiliated Hospital of China Medical University, Department of Neurosurgery, Shenyang, China
}

Corresponding Author: Peizhuo ZANG / E-mail: pzzang@mail.cmu.edu.cn

\begin{abstract}
AIM: To evaluate the use of indocyanine green (ICG) videoangiography in surgical clipping of paraclinoid aneurysms. aneurysms. The findings on ICG videoangiography were compared with postoperative imaging. each case. Findings on ICG videoangiography matched with postoperative angiography.

CONCLUSION: ICG videoangiography is a useful adjunct to the surgical management of paraclinoid aneurysms.

KEYWORDS: Paraclinoid aneurysm, Indocyanine green videoangiography, Clipping
\end{abstract}

MATERIAL and METHODS: Intraoperative ICG videoangiography was used as a surgical adjunct in 60 patients with 65 paraclinoid

RESULTS: All 65 paraclinoid aneurysms were clearly identified by intraoperative ICG videoangiography and obliteration was documented in

öz

AMAÇ: Paraklinoid anevrizmaların cerrahi kliplenmesinde indosiyanin yeşil (ICG) videoanjiyografinin kullanımını değerlendirmek.

YÖNTEM ve GEREÇLER: İntraoperatif ICG videoanjiografi cerrahi tedaviye yardımcı olarak 60 hastada tespit edilen 65 paraklinoid anevrizmada kullanıldı. ICG videoanjiyografi bulguları postoperatif görüntülemeyle karşılaştırıldı.

BULGULAR: 65 paraklinoid anevrizmanın hepsi intraoperatif ICG videoanjiografisi ile net bir şekilde ortaya kondu ve her olguda obliterasyon gösterildi. ICG videoanjiyografi bulguları postoperatif anjiyografi bulgularıyla eşleşiyordu.

SONUÇ: ICG videoanjiyografi paraklinoid anevrizmaların cerrahi tedavisinde faydalı bir yardımcıdır.

ANAHTAR SÖZCÜKLER: Paraklinoid anevrizma, İndosiyanin yeşil videoanjiyografisi, Klipleme

\section{INTRODUCTION}

More recently, indocyanine green (ICG) has been safely adapted from ophthalmic use to neurosurgical applications $(10,12)$. Combined with the use of near-infrared video technology in current microscopes, surgeons can evaluate intraoperative blood flow with a simple intravenous injection. Previous studies have reported its use in cerebral arteriovenous malformations, aneurysms, and extracranial-intracranial bypasses with good results (12-17). This study is dedicated to present our experience with the use of ICG videoangiography in surgical clipping of paraclinoid aneurysm.

\section{MATERIAL and METHODS}

We began using ICG videoangiography at our center in 2003. Between 2003 and 2009, 60 patients with 65 paraclinoid aneurysms were treated by surgical clipping. The indications for surgery vs. endovascular embolization of aneurysms were summarized in Table I. All of these patients underwent intraoperative ICG videoangiography as part of their procedure. All patients underwent surgical exposure of the lesions through a cranial approach. Before and after surgical clipping of the aneurysm, ICG was administered intravenously to identify the aneurysm neck, obliteration rate and patency of the parent internal carotid artery (ICA) (Figure 1A-H). All patients received a $25-\mathrm{mg}$ intravenous dose dissolved in in $5 \mathrm{ml}$ of $0.9 \%$ saline and given as a bolus. The dye was visualized using a Pentero (Carl Zeiss Co., Oberkochen, Germany) or Leica $\mathrm{OH} 4$ (Leica Co. Wetzlar, Germany) fluorescent microscopes. All patients underwent postoperative angiography to verify the results noted on ICG videoangiography.

\section{Aneurysms}

The patients included 45 females and 15 males with ages from 23 to 65 years (mean, 46.1years) (Table II). Twenty-four patients (40\%) had ruptured aneurysms and 36 patients $(60 \%)$ had unruptured aneurysms. Of all the patients who presented with $\mathrm{SAH}$, Hunt and Hess $(\mathrm{H} \& \mathrm{H})$ grade I was 13 , grade II was 6 and grade III was 5 . There were 65 paraclinoid aneurysms. Multiple aneurysms were present in 14 (23.3\%) patients with 
Table I: Indications for Surgical and Endovascular Treatment According to the Literature

\begin{tabular}{|l|l}
\hline Study & Indications \\
Sherif et al. (14) & $\begin{array}{l}\text { Indications for microsurgery were: superior aneurysm projection, giant/large or wide necked } \\
\text { aneurysms and aneurysms at branching sites. Indications for embolisation were: narrow necks, neck } \\
\text { calcification, close aneurysm relation to the clinoid process or adhesion to the distal dural ring, and } \\
\text { aneurysm location in the concavity of the carotid siphon curve. }\end{array}$ \\
Nagasawa et al. (5) & $\begin{array}{l}\text { Microsurgery would be more advantageous for cases where the neck is broad and where the } \\
\text { topography concerning aneurysmal multiplicity or the branching site of the ophthalmic artery is not } \\
\text { fully understood by preoperative imaging. }\end{array}$
\end{tabular}

5 patients harboring bilateral "mirror aneurysms". A posterior communicating artery aneurysm was the most common associated aneurysm, as seen in 3 of the 14 patients, followed by anterior communicating artery aneurysm in 2, cavernous aneurysm in 2 and middle cerebral artery aneurysm in 2. Of the 14 patients with additional associated aneurysms, the subarachnoid hemorrhage (SAH) was caused by the associated aneurysm in $50 \%$ of the patients (7/14). Giant aneurysms ( $>25$ $\mathrm{mm}$ ) were seen in $16(26.7 \%)$ patients. Aneurysm locations according to Barami's classification ${ }^{1}$ were summarized in Table III. All patients receive surgical treatments. DSA is performed for clinical diagnosis and postoperative follow-up examination.

\section{Surgical Approach}

Rupture aneurysm, giant aneurysm and superiority body-side quantitative aneurysms were treated with priority. Pterional craniotomy is performed and the Sylvian cistern is opened. The proximal and distal dural rings are resected. The sphenoid crest is removed and if necessary, anterior clinoid process, the superior and lateral wall of optic canal would be removed for exposure of paraclinoid aneurysm. Yasargil aneurysm clips (Aesculap Co. Ltd.) are chosen for aneurysm clipping. In patients with rupture or giant aneurysms, the proximal and distal parts of the ICA are successively clipped temporarily

Table II: Demographics

\begin{tabular}{|l|c|}
\hline No. of patients & 60 \\
\hline Sex (M/F) & $15 / 45$ \\
\hline Age (mean/range) years & $46.1 / 23-65$ \\
\hline
\end{tabular}

(Figure 1A-H). After the aneurysm is clipped, the temporary clips are dismantled from the distal to the proximal part.

\section{RESULTS}

There was 1 death in the series, giving an overall mortality of $1.7 \%(1 / 60)$. This patient had a $\mathrm{H} \& \mathrm{H}$ grade III SAH with intracranial hematoma. Other complications were meningitis (1 patient), deterioration in vision (1 patient), and deep venous thrombosis ( 2 patients), which were managed accordingly, yielding an overall procedure-related morbidity of $6.7 \%(4 / 60)$, most of which was transient. In all cases, ICG videoangiography precisely demonstrated the aneurysm and documented its obliteration. There was no complication with the use of ICG. Postoperative angiography confirmed aneurysm obliteration.

\section{Follow-Up}

Follow-up ranged from 2 to 72 months (mean, 26.7 months). Outcome was graded according to the Glasgow Outcome Scale (GOS) as described originally by Jennett and Bond (5). A total of $98.3 \%$ of patients had a good outcome (GOS 4 or 5). Most patients (94\%) had normal or improved vision after surgery.

\section{DISCUSSION}

Currently, intraoperative microscopes are modified to allow visualization of ICG (11). Since 2003, ICG has been used as an adjunct to surgical clipping of intracranial aneurysms (10). In 2005, Raabe et al (12) demonstrated that ICG corresponds to DSA in approximately $90 \%$ of cases, with only $2.7 \%$ surgically significant differences in aneurysm cases. In these cases, the time for ICG videoangiography is 5 to 10 minutes. We found

Table III: Aneurysm Locations According to Barami's Classification

\begin{tabular}{|c|c|c|c|c|c|}
\hline la & $\mathrm{C} 6$ & Superior & Ophthalmic & Medial or lateral to the optic nerve & 18 \\
\hline $\mathrm{lb}$ & C6 & Superior & None & Lateral to the ophthalmic nerve & 26 \\
\hline II & C6 & Ventral & None & Dome projects into cavernous sinus roof & 8 \\
\hline Illa & C6 & Medial & superior hypophyseal aneurysms & $\begin{array}{l}\text { Carotid cave aneurysm projects over } \\
\text { diaphragma sellae }\end{array}$ & 0 \\
\hline IIIb & $\mathrm{C} 5$ & Medial & superior hypophyseal aneurysms & Transitional aneurysm infradiaphragmatic & 1 \\
\hline IV & $\mathrm{C} 5$ or $\mathrm{C} 6$ & Ventral & None & $\begin{array}{l}\text { Giant aneurysm extends between } \mathrm{C} 5 \text { and } \mathrm{C} 6 \\
\text { segments. Widens distal dural ring }\end{array}$ & 12 \\
\hline
\end{tabular}



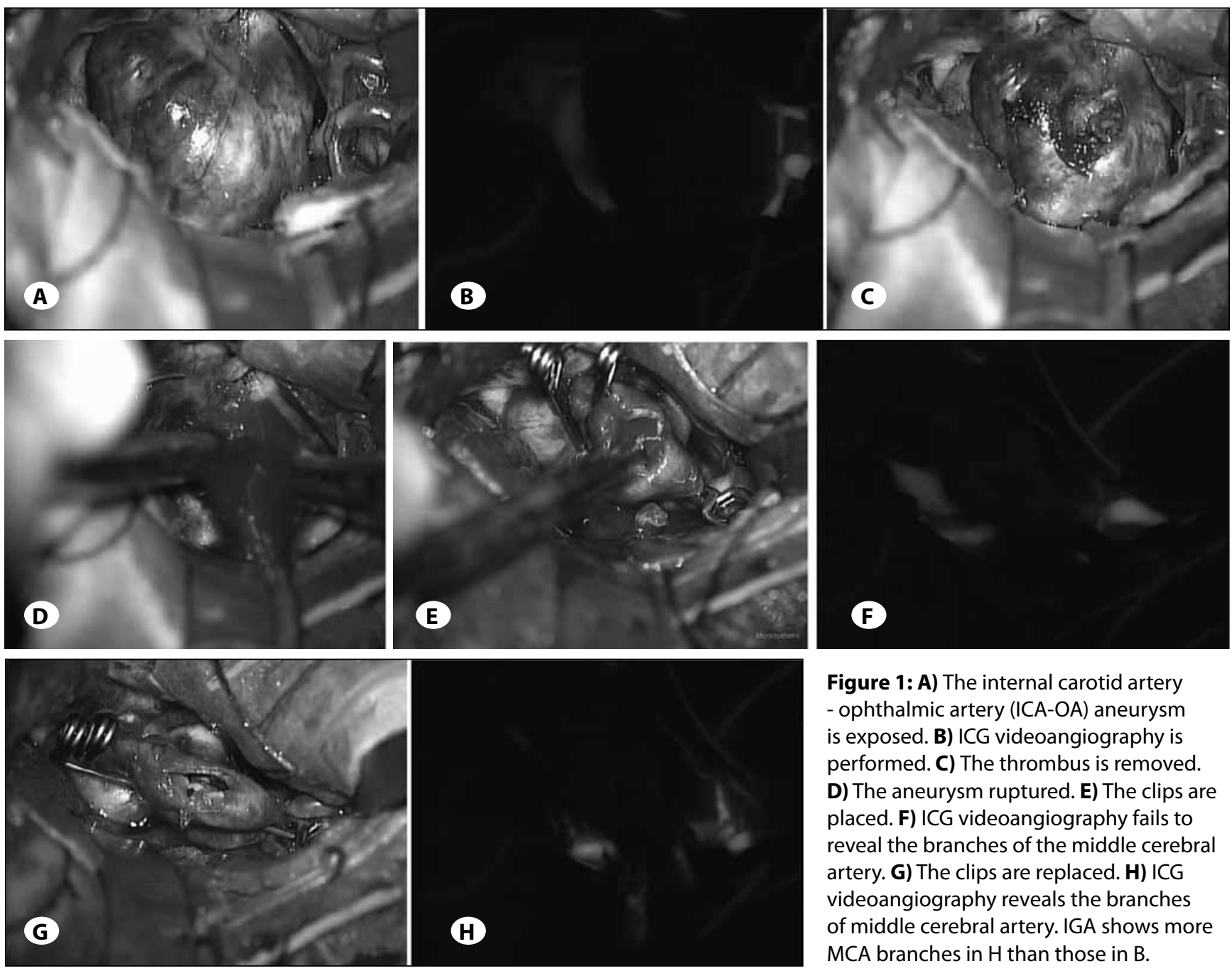

Figure 1: A) The internal carotid artery - ophthalmic artery (ICA-OA) aneurysm is exposed. B) ICG videoangiography is performed. C) The thrombus is removed. D) The aneurysm ruptured. E) The clips are placed. F) ICG videoangiography fails to reveal the branches of the middle cerebral artery. G) The clips are replaced. H) ICG videoangiography reveals the branches of middle cerebral artery. IGA shows more MCA branches in $\mathrm{H}$ than those in $\mathrm{B}$.

that intraoperative ICG matched to postoperative angiography in all 60 cases. In previous studies, ICG videoangiography only added 1 to 3 minutes to the operating time. ICG was safe and no complication was found in our patient series. Although none of our patients had postoperative imaging demonstrating deficiencies in the ICG videoangiogram, it is important to note that the ICG can only be observed under the operating microscope. Therefore, it is important to expose the aneurysm for documentation of complete obliteration.

Using ICG videoangiography, the aneurysm enwrapped by fibrous tissue could be revealed clearly and clipped tentatively. After the fibrous tissue is removed, ICG videoangiography is performed again to determine whether aneurysm is completely clipped. If necessary, the clips are readjusted until the aneurysm is confirmed to be completely clipped and the parent artery and its branches are confirmed to be patent. For a partially thrombosed aneurysm, ICG videoangiography can ascertain the neck of the aneurysm before clipping for facilitating complete clipping. In patients with giant paraclinoid aneurysms with thrombus, the thrombus should be completely removed before the ICA is reconstructed. When the thrombus region is confirmed, aneurysm rupture could be predicted while the neurosurgeon removed the thrombus. Accordingly, sudden hemorrhage could be controlled in time. Furthermore, hemodynamic changes could be witnessed by ICG videoangiography: reverse blood flow firstly appears in the distal part of the ICA then flushes into the aneurysm sac; as the blood flow increases, the vortices begin to take shape. Under ICG videoangiography, real time blood flow vortices can be witnessed. Many papers have been published on surgery for paraclinoid aneurysms $(2-4,6,7,9,13-15,18)$. The mean age of the patients in these studies is $42-50$ years and the SAH rate is $0-80.8 \%$, with mostly large and giant but some small aneurysms, which are comparable to those in our study. The studies report varied mortality from 0 to $13.8 \%$ and morbidity up to $26.8 \%$. The complication rates associated with surgical treatment are $0 \%-25 \%$ and the complete obliteration rates of aneurysms are $66.7 \%-100 \%$. Despite the new advantages and improvement in surgical techniques, there remains a significant morbidity and mortality associated with surgical treatment of these aneurysms. Ng PY et al. have used balloon 
occlusion and suction decompression as adjunct in $64 \%$ cases of large paraclinoid aneurysms and complete aneurysm obliteration was achieved in $82 \%$ of the cases (8). However, we did not use the endovascular technique intraoperatively. Our group of paraclinoid aneurysms, which includes small, large and giant aneurysms, had a procedure-related morbidity of $6.7 \%$, and mortality of $1.7 \%$. This compares favorably with the previously reported surgical series.

\section{CONCLUSIONS}

We have found ICG videoangiography to be a useful adjunct to surgical management of paraclinoid aneurysms. It is useful in monitoring hemodynamic changes and improves prognosis for paraclinoid aneurysms.

\section{REFERENCES}

1. Barami K, Hernandez VS, Diaz FG, Guthikonda M: Paraclinoid carotid aneurysms: Surgical management, complications, and outcome based on a new classification scheme. Skull Base 13: 31-41,2003

2. Beretta F, Andaluz N, Zuccarello $M$ : Aneurysms of the ophthalmic (C6) segment of the internal carotid artery: Treatment options and strategies based on a clinical series. J Neurosurg Sci 48:149-156, 2004

3. Boet R, Wong GK, Poon WS, Lam JM, Yu SC: Aneurysm recurrence after treatment of paraclinoid/ophthalmic segment aneurysms--a treatment-modality assessment. Acta Neurochir (Wien) 147:611-616,2005

4. Fries G, Perneczky A, van Lindert E, Bahadori-Mortasawi F: Contralateral and ipsilateral microsurgical approaches to carotid-ophthalmic aneurysms. Neurosurgery 41: 333-343,1997

5. Jennett $B$, Bond $M$ : Assessment of outcome after severe brain damage. A practical scale. Lancet 1:480-484, 1975

6. Nagasawa S, Kawabata S, Deguchi J, Kuroiwa T, Ohta T, Tsuda E: Microsurgical results of paraclinoid aneurysms of the internal carotid artery: Microsurgery versus intravascular surgery. No Shinkei Geka 27:809-816,1999

7. Nagasawa S, Ohta T, Tsuda E: Surgical results and the related topographic anatomy in paraclinoid internal carotid artery aneurysms. Neurol Res 18:401-408,1996

8. Ng PY, Huddle D, Gunel M, Awad IA: Intraoperative endovascular adjunct in microsurgical clipping of paraclinoid aneurysms. J Neurosurg 93: 554-560, 2000
9. Ohnishi $\mathrm{H}$, Kosimae $\mathrm{N}$ : Surgical management of cerebral aneurysms in comparison with endovascular treatment. Interv Neuroradiol 4(Suppl 1):149-152,1998

10. Raabe A, Beck J, Gerlach R, Zimmermann M, Seifert V: Nearinfrared indocyanine green video angiography: $A$ new method for intraoperative assessment of vascular flow. Neurosurgery 52:132-139,2003

11. Raabe A, Beck J, Seifert V: Technique and image quality of intraoperative indocyanine green angiography during aneurysm surgery using surgical microscope integrated nearinfrared video technology. Zentralbl Neurochir 66:1-8,2005

12. Raabe A, Nakaji P, Beck J, Kim LJ, Hsu FP, Kamerman JD, Seifert V, Spetzler RF: Prospective evaluation of surgical microscopeintegrated intraoperative near-infrared indocyanine green videoangiography during aneurysm surgery. Neurosurgery 103:982-989,2005

13. Raco A, Frati A, Santoro A, Vangelista T, Salvati M, Delfini $\mathrm{R}$, Cantore $\mathrm{G}$ : Long-term surgical results with aneurysms involving the ophthalmic segment of the carotid artery. J Neurosurg 108:1200-1210,2008

14. Sharma BS, Kasliwal MK, Suri A, Sarat Chandra P, Gupta A, Mehta VS: Outcome following surgery for ophthalmic segment aneurysms. J Clin Neurosci 17:38-42,2010

15. Sherif C, Gruber A, Dorfer C, Bavinzski G, Standhardt H, Knosp E: Ruptured carotid artery aneurysms of the ophthalmic (C6) segment: Clinical and angiographic long term follow-up of a multidisciplinary management strategy. J Neurol Neurosurg Psychiatry 80:1261-1267,2009

16. Takagi Y, Kikuta K, Nozaki K, Sawamura K, Hashimoto N: Detection of a residual nidus by surgical microscopeintegrated intraoperative near-infrared indocyanine green videoangiography in a child with a cerebral arteriovenous malformation. J Neurosurg 107(5 Suppl):416-418,2007

17. Woitzik J, Horn P, Vajkoczy P, Schmiedek P: Intraoperative control of extracranial intracranial bypass patency by nearinfrared indocyanine green videoangiography. J Neurosurg 102:692-698,2005

18. Zhao J, Wang S, Zhao Y, Sui D, Zhang Y, Tang J, Lui W: Microneurosurgical management of carotid-ophthalmic aneurysms. J Clin Neurosci 13:330-333,2006 